\title{
AVALIAÇÃO DAS CONDIÇÕES HIGIÊNICO-SANITÁRIAS DE LEITE CRU E QUEIJO COALHO COMERCIALIZADOS EM MERCADOS PÚBLICOS NO NORTE DO PIAUÍ
}

\section{Jhones do Nascimento Dias}

Mestre em Biotecnologia pela Universidade Federal do Piauí - UFPI, Teresina (PI), Brasil.

\section{Laíza Lima Fontinele}

Graduada em Biomedicina pela Universidade Federal do Piauí - UFPI, Teresina (PI), Brasil.

E-mail: laizalima_@hotmail.com

\section{Stella Maris de Oliveira Machado}

Graduada em Biomedicina pela Universidade Federal do Piauí, Campus Ministro Reis Velloso - CMRV-UFPI, Parnaíba (PI), Brasil.

\section{Jefferson Soares de Oliveira}

Doutor em Bioquímica pela Universidade Federal do Ceará - UFC; Docente Adjunto III, lotado no Curso de Bacharelado em Biomedicina da Universidade Federal do Piauí, Campus Ministro Reis Velloso - CMRV-UFPI; membro efetivo dos programas de Mestrado em Biotecnologia e Ciências Biomédicas CMRV-UFPI, Paranaíba, (PI), Brasil.

\section{Gustavo Portela Ferreira}

Doutor em Ciências Biológicas: área Microbiologia, pelo ICB, na Universidade Federal de Minas Gerais UFMG, Brasil; Membro efetivo dos Mestrado em Biotecnologia e do Mestrado em Ciências Biomédicas; Docente adjunto II, da Universidade Federal do Piauí, Campus Ministro Reis Velloso - CMRV-UFPI, Parnaíba (PI), Brasil.

\section{Anna Carolina Toledo da Cunha Pereira}

Doutora em Ciências Biológicas (Microbiologia) pela Universidade Federal de Minas Gerais - UFMG; Docente Adjunto IV, Membro efetivo e orientadora do Mestrado em Ciências Biomédicas da Universidade Federal do Piauí - UFPI, Brasil.
RESUMO: A qualidade microbiológica do leite cru e do queijo coalho está diretamente relacionada com a produção e comercialização do produto. Esta pesquisa objetivou avaliar as condições higiênicosanitárias por meio da deteç̧ão de microrganismos indicadores de contaminação de leite cru e queijo coalho comercializados em mercados públicos da cidade de Parnaíba, Piauí. Foram coletadas 16 amostras de leite cru e 16 amostras de queijo coalho (8 conservadas por refrigeração e 8 sem conservação) em quatro mercados públicos distintos, no período de abril a outubro de 2012 . $\mathrm{Na}$ análise do leite cru, 11 das 16 amostras apresentaram números elevados tanto de coliformes totais como termotolerantes. Com relação à análise do queijo coalho, das 16 amostras 12 apresentavam índices elevados de coliformes totais, sendo que 11 estavam em desacordo com os padrões estabelecidos pela lei vigente da ANVISA. A conservação do queijo também foi avaliada como um parâmetro. Os resultados obtidos mostraram que o leite cru e o queijo coalho, comercializados na cidade de Parnaíba, estão sendo manipulados sob condições higiênicosanitárias insatisfatórias, resultando em um produto final com elevados números de microrganismos indicadores de contaminação, ocasionando um risco para a saúde pública.

PALAVRAS-CHAVE: Coliformes; Contaminação de Alimentos; Laticínios.

\section{EVALUATION OF HYGIENE-SANITARY CONDITIONS OF RAW MILK AND RENNET CHEESE SOLD IN PUBLIC MARKETS IN NORTHERN PIAUÍ, BRAZIL}

\begin{abstract}
The microbiological quality of raw milk and rennet cheese is directly related to the production and commercialization of the product. Current research evaluated the hygiene-sanitary conditions by detecting microorganisms that indicate contamination of raw milk and rennet cheese commercialized in public markets in Parnaíba PI Brazil. Sixteen samples of raw milk and 16 samples of rennet cheese $(8$ samples kept under refrigeration and 8 without) were collected in four different public outlets between April and October 2012. Eleven out of 16 samples of raw milk had a high number of total and thermotolerant coliforms. Twelve out of the 16 samples of rennet cheese had high total coliforms, with eleven exceeding standards by the health department ANVISA. Cheese conservation was also assessed and results revealed that raw milk and rennet cheese are commercialized in Parnaiba without hygiene and sanitary precautions. The final product exhibited a high number of microorganisms indicating contamination, with great risks for public health.
\end{abstract}




\section{INTRODUÇÃO}

Mais de duzentas doenças são transmitidas por meio de alimentos contaminados. Sendo assim, a contaminação alimentar é considerada um risco à saúde pública (SOUSA, 2008). Produtos alimentícios comercializados em mercados públicos, apesar de contribuírem na renda local, podem representar risco à saúde dos consumidores, pois muitos desses alimentos são manipulados e conservados de forma inadequada (CARDOSO; SANTOS; SILVA, 2009). Os alimentos de origem animal são os mais envolvidos em surtos alimentares (ZOCCHE; BASTOS; SILVA, 2010). Entre os produtos mais consumidos estão o leite cru e seus derivados. Estes alimentos possuem alto valor nutricional, o que torna a sua composição propícia à proliferação exacerbada de microrganismos, quando armazenada de forma inadequada (BENDAHOU et al., 2008).

A carga bacteriana do leite cru deriva tanto do animal como dos equipamentos e utensílios utilizados durante o seu processamento. Carga esta que aumenta de acordo com o armazenamento inadequado do produto (CAMPOS et al., 2006; PINTO; MARTINS; VANETTI, 2006; AGARWAL et al., 2012). No Brasil, a comercialização do leite cru direta ao consumidor é proibida de acordo com o Decreto $n^{0} 66.183$, de 05 de fevereiro de 1970, porém, este produto ainda é bastante comercializado (SOARES et al., 2010). Apesar da existência de outras opções, sabese que este produto é muito consumido pela população, justificando a importância de pesquisas relacionadas ao controle de qualidade desse alimento (NERO; MAZIERO; BEZERRA, 2003).

Entre os laticínios mais consumidos na região Nordeste está o queijo do tipo coalho, que apresenta grande importância tanto econômica como nutricional na região. A produção do queijo é geralmente realizada de forma artesanal em pequenas e médias indústrias onde as técnicas de boas práticas de produção geralmente são negligenciadas, o que gera um produto de qualidade insatisfatória (CAVALCANTE et al., 2007; ZAFFARI; MELLO; COSTA, 2007; FREITAS FILHO et al., 2009).

Frequentemente são isolados nestes alimentos microrganismos pertencentes ao grupo dos coliformes, que estão vinculados principalmente na aceleração do processo de deterioração dos alimentos. Quando presentes em elevadas concentrações, estas bactérias indicam prováveis falhas em alguma etapa de processamento que vai desde a fabricação, o transporte, a estocagem até a comercialização (FEITOSA et al., 2003).

O baixo Parnaíba localiza-se ao extremo Norte do Estado do Piauí, estando às margens do rio Parnaíba. É a região que concentra a maior produção de leite do Estado do Piauí. Parnaíba, segunda cidade mais populosa do Estado, faz parte com mais doze municípios da bacia leiteira do Parnaíba. Desta forma o presente estudo objetivou avaliar as condições higiênico-sanitárias através da detecção de microrganismos indicadores de contaminação de leite cru e queijo coalho comercializados em mercados públicos da cidade de Parnaíba (PI). Por meio da análise de índices de contaminação, os resultados encontrados no presente estudo oferecem uma base de como esses produtos estão sendo fabricados e/ou comercializados na cidade.

\section{METODOLOGIA}

O presente estudo de caráter quantitativo ocorreu no período de abril a outubro de 2012, onde pretendeu-se avaliar as condições higiênico-sanitárias por meio da detecção de microrganismos indicadores de contaminação em leite cru e queijo coalho, comercializados em quatro mercados públicos da cidade de Parnaíba (PI).

As amostras obtidas para a realização das análises foram coletadas nos mercados públicos de diferentes regiões da cidade, classificados com números de 1 a 4 e as amostras identificadas com uma numeração específica de acordo com o local de venda. As coletas foram realizadas semanalmente onde duas semanas do mês foram destinadas à coleta de leite cru e as outras duas à coleta de queijo coalho. No momento da coleta, foram anotadas em um registro as características referentes ao local de venda tais como o modo de conservação e presença de outros alimentos próximos aos objetos de estudo. Desta forma coletaram-se 16 amostras de queijo do tipo coalho $(100 \mathrm{~g})$ e 16 de leite cru $(500 \mathrm{~mL})$. As amostras foram transportadas em caixas isotérmicas obedecendo a um 
intervalo inferior a 30 minutos do momento da coleta até a realização das análises no laboratório de microbiologia.

A quantificação de coliformes totais e termotolerantes foi realizada através da técnica de tubos múltiplos de acordo com a metodologia proposta por Silva et al. (2010b). Antes do início das análises, a parte externa das embalagens contendo as amostras foi higienizada com álcool $70 \%$ para a remoção de contaminantes externos.

Para a obtenção da unidade analítica do queijo, ocorreu uma maceração da amostra com uma espátula estéril e retirada $25 \mathrm{~g}$ da mistura, sendo esta transferida para um béquer contendo $225 \mathrm{~mL}$ de água peptonada. Para as amostras de leite, foram utilizadas $10 \mathrm{~mL}$ como unidade analítica e misturadas em um bécker com 90 $\mathrm{mL}$ de água peptonada. As amostras foram submetidas à homogeneização por um minuto tornando-se assim a diluição $10^{-1}$. Após a obtenção desta primeira diluição, foram realizadas as diluições seriadas subsequentes até a de $10^{-3}$ onde todas foram utilizadas na análise.

Para a identificação dos microrganismos, utilizou-se o caldo Lauril sulfato triptose (LST) como teste presuntivo e, como teste confirmativo, foi usado o caldo verde brilhante bile $2 \%$ (VB), o qual é utilizado para a contagem de coliformes totais e o caldo $E$. coli (EC) para a contagem de coliformes termotolerantes. A positividade se deu pela formação de gás e turvação do meio.

De cada uma das diluições preparadas, foram inoculados $1 \mathrm{~mL}$ em uma série de três tubos contendo 10 $\mathrm{mL}$ de caldo LST, com incubação a uma temperatura de $35-37{ }^{\circ} \mathrm{C}$ por 48 horas. Quando os tubos contendo LST apresentaram positividade, foram realizados os testes confirmatórios utilizando caldo VB para a contagem de coliformes totais e caldos EC para a contagem de coliformes termotolerantes. Para isto, realizam-se alçadas dos tubos LST positivos e inocula-se nos respectivos tubos contendo VB e EC, seguindo as diluições que apresentaram positividade. Os tubos com caldo VB foram incubados a $35-36{ }^{\circ} \mathrm{C}$ durante 24 horas, enquanto os tubos com caldo EC foram incubados a $45-46{ }^{\circ} \mathrm{C}$ em um período de 24 horas. A Figura 1 esquematiza a técnica de tubos múltiplos.

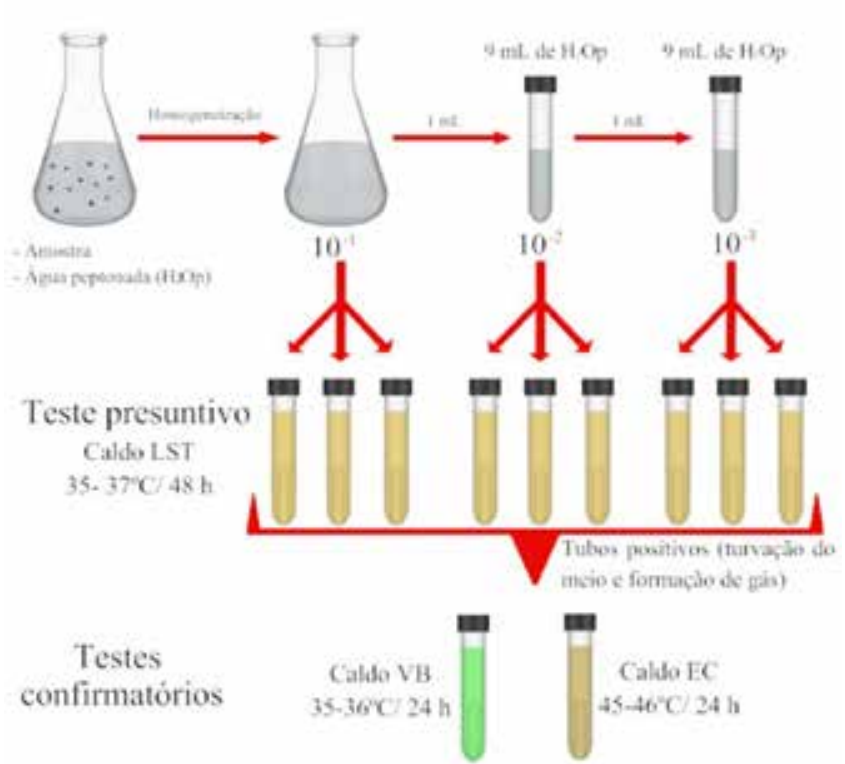

Figura 1. Técnica de tubos múltiplos realizada nas amostras de leite cru e queijo coalho.

Os resultados foram obtidos por meio do número de tubos positivos de cada diluição com base na tabela estatística de Hoskins para três tubos. E são expressos como número mais provável (NMP). Como parâmetro de comparação para o queijo coalho, foi considerado o limite estabelecido pela legislação vigente da ANVISA. Já para o leite cru não há parâmetros para se comparar, pois não existe legislação vigente, o que leva à proibição da comercialização do mesmo.

\section{RESULTADO}

Das 16 amostras analisadas de leite cru, 100\% apresentaram-se positivas para coliformes totais e termotolerantes. Dessas, 68,7\% $(n=11)$ apresentaram números elevados de coliformes. De acordo com a tabela de Hoskins os valores apresentados ultrapassaram 1.100 $\mathrm{NMP} / \mathrm{mL}$, portanto, impróprias para o consumo. Destas, 04 amostras eram provenientes do mercado I, 03 do mercado II, 01 do mercado III e 03 comercializadas no mercado IV, como mostra a Tabela 1. 
TABELA 1. Contagem de coliformes totais e termotolerantes em leite cru de quatro mercados da cidade de Parnaíba (PI)

\begin{tabular}{l|ccc|ccc}
\hline \multicolumn{3}{c}{ Coliformes totais } & \multicolumn{2}{c}{ Coliformes termotolerantes } \\
\hline NMP/mL & $<3,0$ a 240 & 290 a 460 & Até 1.100 e $>1.100$ & $<3,0$ a 240 & 290 a 460 & Até 1.100 e $>1.100$ \\
\hline Mercado I & - & - & $25 \%$ & - & - & $25 \%$ \\
Mercado II & $6 \%$ & - & $19 \%$ & $6 \%$ & - & $19 \%$ \\
Mercado III & $6 \%$ & $13 \%$ & $6 \%$ & $6 \%$ & $13 \%$ & $6 \%$ \\
Mercado IV & $6 \%$ & - & $19 \%$ & $6 \%$ & - & $19 \%$ \\
\hline
\end{tabular}

Foram analisadas 16 amostras de queijo termotolerantes nas amostras de queijo demonstrou coalho, das quais $75 \%(n=12)$ apresentavam elevadas que $68,7 \%(n=11)$ das amostras apresentavam valores contagens de coliformes totais. Isto indica condições que ultrapassam os limites estabelecidos pela legislação insatisfatórias de higiene em alguma etapa de produção vigente da ANVISA. Na Tabela 2 podem ser observados os ou armazenamento. A contagem de coliformes resultados da análise do queijo coalho.

TABELA 2. Contagem de coliformes totais e termotolerantes em amostras de queijo coalho em quatro mercados da cidade de Parnaíba (PI)

\begin{tabular}{l|ccc|ccc}
\hline \multicolumn{3}{c}{ Coliformes totais } & \multicolumn{3}{c}{ Coliformes termotolerantes } \\
\hline $\mathrm{NMP} / \mathrm{mL}$ & $<3,0$ a 240 & $290 \mathrm{a} 460$ & Até $1.100 \mathrm{e}>1.100$ & $<3,0$ a 240 & 290 a 460 & Até $1.100 \mathrm{e}>1.100$ \\
\hline Mercado I & - & $6 \%$ & $19 \%$ & - & $6 \%$ & $19 \%$ \\
Mercado II & $12 \%$ & - & $13 \%$ & $13 \%$ & $6 \%$ & $6 \%$ \\
Mercado III & - & $6 \%$ & $19 \%$ & $6 \%$ & - & $19 \%$ \\
Mercado IV & - & - & $25 \%$ & - & - & $25 \%$ \\
\hline
\end{tabular}

Padrão estabelecido pela ANVISA: 5x10² NMP/g (Brasil, 2001).

Das 16 amostras de queijo coalho coletadas, que estavam armazenadas em temperatura ambiente, apenas 08 encontravam-se refrigeradas no momento da como mostra a Tabela 3. Das oito amostras refrigeradas, coleta. $\mathrm{Na}$ análise destas amostras fora observado um quatro estavam fora dos padrões legais, e das amostras índice menor de contaminação quando comparadas às sem refrigeração, sete foram consideradas impróprias.

TABELA 3. Contagem de coliformes totais e termotolerantes em queijo coalho conservado por refrigeração e sem conservação

\begin{tabular}{l|c|c|c|c|c|c|}
\hline \multicolumn{4}{|c|}{ Coliformes totais } & \multicolumn{3}{c|}{ Coliformes termotolerantes } \\
\hline $\mathrm{NMP} / \mathrm{mL}$ & $<3,0 \mathrm{a} 240$ & $290 \mathrm{a} 460$ & Até $1.100 \mathrm{e}>1.100$ & $<3,0 \mathrm{a} 240$ & 290 a 460 & Até $1.100 \mathrm{e}>1.100$ \\
\hline Refrigerado & $13 \%$ & $6 \%$ & $31 \%$ & $19 \%$ & $6 \%$ & $25 \%$ \\
\hline Não refrigerado & - & $6 \%$ & $44 \%$ & - & $6 \%$ & $44 \%$ \\
\hline
\end{tabular}

Padrão estabelecido pela ANVISA: 5x10² NMP/g Fonte: (Brasil, 2001). 


\section{DISCUSSÃO}

Os mercados públicos são pontos para comercialização de diversos gêneros alimentícios. Dentre eles carnes, frutas, legumes, verduras, leite e seus derivados constituem os principais produtos comercializados. O estudo realizou-se nos quatro mercados públicos de maior porte e maior fluxo de clientes dentre os demais mercados, localizados em diversos pontos do município de Parnaíba, Piauí. Estes mercados atraem diariamente centenas de consumidores interessados na grande variedade de produtos alimentícios expostos contribuindo, dessa forma, com a renda local dos comerciantes. Dentre os alimentos comercializados está o leite cru, que apesar de ser proibida a venda diretamente ao consumidor, tal prática ainda é realizada, principalmente por pequenos produtores leiteiros (BADINI et al., 1996).

Segundo Claeys et al. (2013), o leite cru é um excelente meio de proliferação microbiana, devido ao seu alto valor nutricional, $\mathrm{pH}$ neutro, teor de água e temperatura adequados à proliferação dos microrganismos. Isto acaba sendo uma problemática de saúde pública no momento em que o leite cru tornarse comercializado, pois o mesmo passa a ser um veículo causador de doenças transmitidas por alimentos. No Brasil, essa prática é comum, pois está associada a fatores culturais, regionais e sociais além de ter as questões de praticidade, preço baixo e a ideia errônea de que são alimentos saudáveis por terem vindo direto do produtor (LYE et al., 2013; MONTANHINI; HEIN, 2013).

Todas as amostras de leite deste estudo estavam armazenadas em latões de $50 \mathrm{~L}$ a temperatura ambiente. Maciel et al. (2008) avaliaram amostras de leite cru comercializadas na cidade de Itapetinga, Bahia, armazenadas em latões e estocados em temperatura ambiente; os resultados obtidos por Maciel corroboram com os encontrados nesta pesquisa, sendo observados elevados índices de coliformes totais e termotolerantes. De acordo com Longhi et al. (2010), a contaminação do leite se dá por falhas durante a ordenha. Entretanto, os equipamentos utilizados, o transporte e o armazenamento estão entre as principais fontes de contaminação. Segundo Montanhini e Hein (2013), além da contaminação do leite ser um risco à saúde, a utilização do mesmo para a produção de derivados os torna impróprios para o consumo, pois os métodos de processamento utilizados podem reduzir a carga bacteriana, mas não as eliminam totalmente. Stamford et al. (2006) afirmam que todos os alimentos deveriam passar por testes microbiológicos pois refletiriam as condições higiênico-sanitárias sobre a produção, estocagem, transporte e manuseio.

$\mathrm{Na}$ pesquisa realizada por Alves et al.(2009) detectou-se números elevados de coliformes totais e termotolerantes no leite cru comercializado informalmente na cidade de São Luís, Maranhão, sendo que algumas amostras possuíam valores que se encontravam na margem de $10^{3}$ a $10^{7} \mathrm{NMP} / \mathrm{mL}$ tanto de coliformes totais como de termotolerantes. Em uma pesquisa realizada na cidade de Solânea, na Paraíba, por Amaral e Santos (2011), as amostras de leite cru comercializadas por ambulantes apresentaram valores superiores a $1.100 \mathrm{NMP} / \mathrm{mL}$ de coliformes totais e termotolerantes. Tais resultados corroboram com os dados encontrados neste estudo, demonstrando que o leite cru não é apropriado à venda direta ao consumidor, sem antes ser submetido a um processamento.

Os resultados demonstram a importância dos processos de tratamento do leite cru, pois esse alimento possui alta taxa de microrganismos. Luz et al. (2011) ressaltam que mesmo quando o leite com alta carga bacteriana passa pelo processo de pasteurização, uma parcela da microbiota inicial continua viável. Portanto, quanto maior a contaminação do leite antes da pasteurização, maior será a permanência de células bacterianas viáveis. Desta forma, a má conservação e manipulação do leite antes da sua comercialização contribuem para o aumento exponencial da sua microbiota. Tal fato é corroborado pelos resultados demonstrados neste artigo, onde $100 \%$ das amostras de leite cru analisadas obtiveram positividade para coliformes totais e termotolerantes e $68,7 \%$ apresentaram números elevados, valores estes que ultrapassaram 1.100 $\mathrm{NMP} / \mathrm{mL}$.

O principal derivado do leite comercializado nos mercados públicos de Parnaíba é o queijo coalho, que se destaca pela sua grande produção e importância econômica. O processamento, em sua grande maioria, 
é realizado por pequenas e médias fazendas nas quais não há o uso de tecnologia adequada e suas técnicas de produção são feitas seguindo um modelo de fabricação artesanal.

Por falta de padronização na fabricação e o uso de leite cru como matéria-prima os riscos de contaminação do queijo coalho são elevados. Além disso, o armazenamento, o transporte e a comercialização influenciam nos riscos (CAVALCANTE et al., 2007; FREITAS et al., 2009). Segundo Paula et al. (2012), a partir da padronização da técnica e da utilização de leite pasteurizado, o queijo coalho teria um menor risco de contaminação, tornando-o mais apropriado para o consumo.

Entre as amostras de queijo coalho avaliadas, 75\% apresentavam elevadas contagens de coliformes totais. Essa elevada taxa indica condições insatisfatórias de higiene em alguma etapa de produção ou após esta. Em relação à contagem de coliformes termotolerantes, 68,7\% amostras apresentavam valores que ultrapassam os limites estabelecidos pela legislação vigente. Os resultados corroboram aos encontrados por Santana, Santos e Martinez (2008) em trabalho realizado na cidade de Aracaju - Sergipe, em que 93,3\% das amostras de queijo coalho avaliadas estavam fora dos padrões legais. Silva et al. (2010a) encontraram números elevados em todas as amostras analisadas de três indústrias de laticínios do sertão de Alagoas, com elevadas contagens de coliformes totais e termotolerantes onde, nesta última, os valores tornavam as amostras impróprias para o consumo.

A refrigeração constitui em um método simples e prático para inibir a proliferação bacteriana, desta forma as amostras de queijo coalho que estavam conservadas por refrigeração, apresentaram um número menor de coliformes em relação às que estavam a temperatura ambiente.

Das amostras de queijo coalho conservadas por refrigeração 31\% apresentaram valores acima do limite para coliformes totais, enquanto que nas amostras não refrigeradas, $44 \%$ apresentaram valores acima do limite. Para coliformes termotolerantes, 25\% das amostras refrigeradas apresentaram valores acima do permitido, enquanto $44 \%$ das não refrigeradas excederam o limite.

Os resultados encontrados divergiram dos citados por Dantas (2012), em pesquisa feita na cidade de Patos, na Paraíba, onde das 13 amostras estudadas, sete eram expostas à temperatura ambiente e cinco eram conservadas por refrigeração, entretanto, todas as amostras apresentavam-se fora dos padrões estabelecidos pela ANVISA.

Os resultados evidenciam a importância de um processamento adequado que reduza a contaminação microbiana e, consequentemente, a redução dos riscos aos consumidores. De acordo com os dados obtidos, pressupõe-se que o abastecimento com leite cru e queijo coalho realizado pelos produtores nos mercados de Parnaíba provavelmente não utilizam de técnicas apropriadas para conservação e manuseio dos mesmos. O manejo durante a comercialização também interfere na carga microbiológica dos alimentos, onde medidas simples, como conservar o produto refrigerado, acabam consistindo em uma importante ferramenta no controle bacteriano.

\section{CONCLUSÃo}

O elevado número de coliformes totais e termotolerantes detectado no leite cru e no queijo coalho indica uma má qualidade higiênico-sanitária em alguma das etapas de produção ou comercialização desses produtos. O número elevado de amostras de queijo coalho em desacordo com a lei vigente expõe os consumidores a riscos à saúde. $\mathrm{O}$ número baixo de amostras refrigeradas inapropriadas para o consumo em comparação com as que não estavam conservadas demonstra a importância da conservação na diminuição do número de microrganismos patogênicos. Portanto, há uma necessidade de melhoria em boas práticas de produção a fim de reduzir a contaminação na cadeia produtiva desses alimentos visando melhoria na qualidade do produto final.

\section{REFERÊNCIAS}

AGARWAL, A.; AWASTHI, V.; DUA, A.; GANGULY, S.; GARG, V.; MARWAHA, S. S. Microbiological profile of Milk: Impact of Household practices. Indian J Public Health, v. 56, n. 1, p. 88-94, 2012. 
ALVES, L. M. C.; AMARAL, L. A.; CORRÊA, M. R.; SALES, S. S. Qualidade microbiológica do leite cru e de queijo de coalho comercializados informalmente na cidade de São Luís - MA. Pesq Foco, v. 17, n. 2, p. 01-13, 2009.

AMARAL, C. R. S.; SANTOS, E. P. Leite cru comercializado na cidade de Solânea, PB: caracterização físico-química e microbiológica. Rev Bras Produtos Agroindustriais, v. 13, n. 1, p. 07-13, 2011.

BADINI, K. B.; NADER FILHO, A.; AMARAL, L. A.; GERMANO, P. M. L. Risco à saúde representado pelo consumo de leite cru comercializado clandestinamente. Rev Saúde Pública, v. 30, n. 6, p. 549-552, 1996.

BENDAHOU, A.; LEBBADI, M.; ENNANEI, L.; ESSADQUI, F. Z.; ABID, M. Characterization of Staphylococcus species isolated from raw milk and milk products (lbenandjben) in North Morocco. J Infect Dev Ctries, v. 2, n. 3, p. 218225, 2008.

BRASIL, Decreto $\mathrm{n}^{\circ} 66.183$ de 05 de fevereiro de 1970. Regulamenta o Decreto-lei no ${ }^{\circ}$ 923, de 10 de outubro de 1969, que dispõe sobre a comercialização do leite cru. Diário Oficial [da] União, Brasília, DF, 06 fev. 1970.

BRASIL. Resolução RDC ANVISA/MS n ${ }^{\circ} 12$, de 02 de janeiro de 2001. Regulamento Técnico sobre os Padrões Microbiológicos para Alimentos. Diário Oficial [da] União Federativa do Brasil, Brasília, DF, 10 jan. 2001. Seção 1.

CAMPOS, M. R. H.; KIPNIS, A.; ANDRÉ, M. C. D. P. B.; VIEIRA, C. A. S.; JAYME, L. B.; SANTOS, P. P.; SERAFINI, Á. B. Caracterização fenotípica pelo antibiograma de cepas de Escherichia coli isoladas de manipuladores, de leite cru e de queijo "Minas Frescal" em um laticínio de Goiás, Brasil. Ciência rural, v. 36, n. 4, p. 1221-1227, 2006.

CARDOSO, R. C. V.; SANTOS, S. M. C.; SILVA, E. O. Comida de rua e intervenção: estratégias e propostas para o mundo em desenvolvimento. Ciênc Saúde Coletiva, v. 14, n. 4, p. 1215-1224, 2009.

CAVALCANTE, J. F. M.; ANDRADE, N. J.; FURTADO, M. M.; FERREIRA, C. L. L. F.; PINTO, C. L. O.; ELARD, E. Processamento do queijo coalho regional empregando leite pasteurizado e cultura lática endógena. Ciênc Tecnol. Aliment., v. 27, n. 1, p. 205-214, 2007.
CLAEYS, W. L.; CARDOEN, S.; DAUBE, G.; BLOCK, J. D.; DEWETTINCK, K.; DIERICK, K.; ZUTTER, L. D.; HUYGHEBAERT, A.; IMBERECHTS, H.; THIANGE, P.; VANDENPLAS, Y.; HERMAN, L. Raw or heated cow milk consumption: Review of risks and benefits. Food Control, v. 31, n. 1, p. 251-262, 2013.

DANTAS, D. S. Qualidade microbiológica do queijo de coalho comercializado no município de Patos, PB. 2012. 79f. Dissertação (Mestrado em Zootecnia) - Universidade Federal de Campina Grande, Centro de Saúde e Tecnologia Rural, Campina Grande, 2012.

FEITOSA, T.; BORGES, M. F.; NASSU, R. T.; AZEVEDO, É. H. F.; MUNIZ, C. R. Pesquisa de Salmonella sp., Listeria sp. e microrganismos indicadores higiênico-sanitários em queijos produzidos no estado do Rio Grande do Norte. Ciênc Tecnol. Aliment., v. 23, p. 162-165, 2003.

FREITAS FILHO, J. R.; SOUZA FILHO, J. S.; OLIVEIRA, H. B.; ANGELO, J. H. B.; BEZERRA, J. D. C. Avaliação da qualidade do queijo "coalho" artesanal fabricado em Jucati - PE. EXTENSIO: R Eletr. de Extensão, v. 6, n. 8, 2009.

FREITAS, M. F. L.; LUZ, I. S.; PINHEIRO JÚNIOR, J. W.; DUARTE, D. A. M.; VASCONCELOS, A. M. M.; RIBEIRO, A. R.; MOTA, R. A.; BALBINO, T. C. L.; STAMFORD, T. L. M. Detecção de genes toxigênicos em amostras de Staphylococcus spp. isoladas de queijos de coalho. Ciênc Tecnol. Aliment., v. 29, n. 2, p. 375-379, 2009.

LONGHI, R.; MORENO, A. C. P.; REIS, A. B.; OKANO, W.; ARAGON-ALEGRO, L. C.; SANTANA, E. H. W. Perfil dos consumidores de leite cru da cidade de Arapongas - PR. Rev Instit Laticínios Cândido Tostes, v. 65, n. 373, p. 14-19, 2010.

LUZ, D. F.; BICALHO, F. A.; OLIVEIRA, M. V. M.; SIMÕES, A. R. P. Avaliação microbiológica em leite pasteurizado e cru refrigerado de produtores da região do Alto Pantanal Sul-Mato-Grossense. Rev Agrarian, v. 4, n. 14, p. $367-$ 374, 2011.

LYE, Y. L.; AFSAH-HEJRI, L.; CHANG, W. S.; LOO, Y. Y.; PUSPANADAN, S.; KUAN, C. H.; GOH, S. G.; SHAHRIL, N.; RUKAYADI, Y.; KHATIB, A.; JOHN, Y. H. T.; NISHIBUCHI, M.; NAKAGUCHI, Y.; SON, R. Risk of Escherichia coli O157:H7 transmission linked to the consumption of raw milk. Int Food Research J, v. 20, n. 2, p. 1001-1005, 2013. 
MACIEL, J. F.; CARVALHO, E. A.; SANTOS, L. S.; ARAÚJO, J. B.; NUNES, V. S. Qualidade microbiológica de leite cru comercializado em Itapetinga-BA. RBSPA, v. 9, n. 3, p. 443-448, 2008.

MONTANHINI, M. T. M.; HEIN, K. K. Qualidade do leite cru comercializado informalmente no município de Piraí do sul, estado do Paraná, Brasil. Rev Instit Laticínios Cândido Tostes, v. 68, n. 393, p. 10-14, 2013.

NERO, L. A.; MAZIERO, D.; BEZERRA, M. M. S. Hábitos alimentares do consumidor de leite cru de Campo Mourão - PR. Semina: Ci. Agrárias, Londrina, v. 24, n. 1, p. 21-26, 2003.

PAULA, J. C. J.; ALMEIDA, F. A.; PINTO, M. S.; RODRIGUES, T. F.; SOBRAL, D.; MACHADO, G. M. Aproveitamento de soro de queijo de coalho na elaboração de bebida láctea fermentada. Rev Instit Laticínios Cândido Tostes, v. 67, n. 388, p. 25-33, 2012.

PINTO, C. L. O.; MARTINS, M. L.; VANETTI, M. C. D. Qualidade microbiológica de leite cru refrigerado e isolamento de bactérias psicrotróficas proteolíticas. Ciênc Tecnol. Aliment., v. 26, n. 3, p. 645-651, 2006.

SANTANA, R. F.; SANTOS, D. M.; MARTINEZ, A. C. C.; LIMA, Á. S. Qualidade microbiológica de queijo-coalho comercializado em Aracaju, SE. Arq Bras Med Vet Zootec., v. 60, n. 6, p. 1517-1522, 2008.

SILVA, M. C. D.; RAMOS, A. C. S.; MORENO, I.; MORAES, J. O. Influência dos procedimentos de fabricação nas características físico-químicas, sensoriais e microbiológicas de queijo de coalho. Rev Instituto Adolfo Lutz, v. 69, n. 2, p. 214-221, 2010a.

SILVA, N.; JUNQUEIRA, V.C.A.; SILVEIRA, N.F.A.; TANIWAKI, M. H.; SANTOS, R. F.S.; GOMES, R. A.R. Manual de métodos de análise microbiológica de alimentos e água. 4. ed. São Paulo: Varela, 2010b. 133p.

SOARES, K. M. P.; GÓIS, V. A.; AROUCHA, E. M. M.; VERÍSSIMO, A. M. O. T.; SILVA, J. B. A. Hábitos de consumo de leite em três municípios do estado do Rio Grande do Norte. Revista Verde, v. 5, n. 3, p. 160-164, 2010.

SOUSA, C. P. The Impact of Food Manufacturing Practices on Food borne Diseases. Braz Arch Biol Technol., v. 51, n. 4, p. 815-823, 2008.
STAMFORD, T. L. M.; SILVA, C. G. M.; MOTA, R. A.; CUNHA NETO, A. Enterotoxigenicidade de Staphylococcusspp. isolados de leite in natura. Ciênc Tecnol. Aliment., v. 26, n. 1, p. 41-45, 2006.

ZAFFARI, C. B.; MELLO, J. F.; COSTA, M. Qualidade bacteriológica de queijos artesanais comercializados em estradas do litoral norte do Rio Grande do Sul, Brasil. Ciênc Rural, v. 37, n. 3, p. 862-867, 2007.

ZOCCHE, F.; BASTOS, C. P.; SILVA, W. P. Detecção de genes do cluster egcem Staphylococcus aureus isolados de alimentos de origem animal. Ciênc Rural, v. 40, n. 5, p. 1134-1140, 2010.

Recebido em: 20 de maio de 2015 Aceito em: 27 de agosto de 2015 